\title{
Computational thinking for teachers: Development of a localised E-learning system
}

\author{
Ling-Ling Ung ${ }^{\text {a, }}$, Jane Labadin ${ }^{\text {b }}$, Fitri Suraya Mohamad ${ }^{\mathrm{b}}$ \\ ${ }^{\text {a }}$ Faculty of Computer \& Mathematical Sciences, Universiti Teknologi MARA Sabah Branch, Kota Kinabalu Campus, Locked Bag 71, 88997, Kota \\ Kinabalu, Sabah, Malaysia \\ ${ }^{\mathrm{b}}$ Institute of Social Informatics and Technological Innovations Universiti Malaysia Sarawak 94300 Kota Samarahan, Sarawak, Malaysia
}

\section{A R T I C L E I N F O}

\section{Keywords:}

Computational thinking

E-Learning

Information system

Teaching and learning

Teachers

\begin{abstract}
A B S T R A C T
Malaysia has introduced computational thinking skills as part of a curriculum integration update to meet the global trends in 21st-century education, focusing on empowering digital literacy. Nevertheless, a preliminary investigation revealed an apparent lack of understanding of computational thinking skills in general among teachers. The study explores the feasibility of developing a localized E-learning system to train computational thinking skills among teachers. An E-learning system, termed as myCTGWBL, was developed on the basis of a newly proposed conceptual framework to present computational thinking teaching-learning repertoire to the teachers. The hypothesis is that myCTGWBL would develop teachers' computational thinking and its position in teaching-learning understanding. myCTGWBL relevance was tested through DeLone and McLean's information system and Urbach's collaboration quality construct. To determine the success factors, partial least squares structural equation modeling was used. A total of 369 teachers participated in a two-stage survey. Participants' understanding of computational thinking and perceptions were recorded at the pre- and post-intervention phases. Open-ended questions of the surveys were analyzed using a simple text analysis technique. The closedended questions surveys were analyzed using SPSS Statistics 22.0. A significant improvement in teachers' computational thinking teaching-learning repertoire in a relatively short period has been recorded. Teachers also demonstrated increased confidence in the future delivering computational thinking-based lessons. The E-learning conceptual framework has illustrated the predictive power between user intent, user satisfaction, and Computational thinking (CT) knowledge benefits. Results demonstrate that myCTGWBL could be used to guide future planning when establishing CT knowledge acquisition initiatives, particularly among teachers.
\end{abstract}

\section{Introduction}

Computational thinking (CT) is becoming an essential skill for everyone. Several scientists believe that it is a must-have skill in the 21st century, even labeling it as a futuristic skill (Haseski et al., 2018; Wing, 2016). CT helps one build skills that will benefit the workplace and thrive in the demanding and unpredictable environment (Nouri et al., 2019). It is evident when many countries have embedded CT skills into their curriculum (Hsu et al., 2018). Hence, preparing the teachers to face the challenges of teaching CT is crucial.

\footnotetext{
* Corresponding author.

E-mail address: ungli720@uitm.edu.my (L.-L. Ung).
} 